\title{
Derribar los muros. De la historia urbana a los estudios urbanos con perspectiva histórica: propuestas teóricas y metodológicas desde un diálogo interdisciplinar
}

Gerardo Martínez-Delgado. Universidad de Guanajuato, Guanajuato, México.

RESUMEN | La historia urbana ha entablado por naturaleza vínculos con muchos campos del saber, como la arquitectura, el urbanismo, la sociología o la antropología. A pesar de ello, parece pertinente subrayar la necesidad de que, en conjunto, los estudios urbanos amplíen sus diálogos, a fin de que sean un campo común donde la ciudad como objeto de estudio derribe muros disciplinares y conceptuales y la perspectiva histórica cobre mayor relevancia, pero también para que los historiadores se ocupen con mayor energía de la historia de las ciudades y lo hagan con mejores armas metodológicas. El artículo ofrece diversas propuestas aplicadas al trabajo con fuentes, y reflexiones empíricas y teóricas para sortear obstáculos, fortalecer el diálogo entre disciplinas y hacer que la historia urbana (como muchos otros campos de especialización) salga de sus prisiones y laberintos.

PALABRAS CLAVE | historia urbana, transformaciones socioterritoriales, teoría urbana.

ABSTRACT | Urban history has naturally been linked with several fields of knowledge, such as architecture, urbanism, sociology or anthropology. In spite of this, it seems pertinent to underline the need of urban studies to continue to expand dialogues and become a common field, in which the city as object of study, overturns disciplinary and conceptual walls and the historical perspective becomes more relevant. It is also important for historians to attend issues of the history of cities with more energy and with better methodological tools. The article offers a series of proposals applied to work with sources and theoretical reflections to overcome obstacles, to strengthen the dialogue between disciplines and to escape the labyrinths in which urban history and many other fields of specialization have been enclosed to.

KEYWORDS | urban history, socio-territorial transformations, urban theory. 


\section{Introducción}

La historia urbana ha llevado a cuestas pesadas cargas desde que su práctica se empezó a formalizar en la academia, en la década de 1960. Desde afuera ha existido una suerte de "imperialismo" profesional, ya de los arquitectos, ya de los urbanistas $\mathrm{u}$ otras veces de los sociólogos, todos quienes han llegado a suponer que el entendimiento e intervención sobre la ciudad es de su competencia exclusiva o preferente. También desde adentro, desde sus mismos practicantes, se ha puesto en duda la legitimidad epistemológica de la investigación histórica de la ciudad, de la naturaleza de esta como objeto propio de estudio, como una realidad diferente a las que contiene. Se la ha señalado, también, como una entidad incapaz de producir por sí misma cambio alguno (De Terán, 1996; Lepetit, 1996; Mejía, 1998).

Con el paso de las décadas, el número de practicantes, las obras producidas, las asociaciones y congresos y otras expresiones han cobrado vigor y han permitido que la duda epistemológica pase a un segundo plano. El problema, no obstante, se ha trasladado: la historia urbana ha sido víctima de la especialización de la que es hija y se ha fragmentado su antes vago objeto de estudio. "El debilitamiento de una percepción global -anotó Edgar Morin (2007) en una frase muchas veces citada respecto a las ciencias en general- conduce al debilitamiento del sentido de responsabilidad, ya que cada uno tiende a no ser responsable más que de sus tareas especializadas...” (p. 20). En idéntico tono, Anthony Sutcliffe señaló sobre la historia urbana, "hemos ido demasiado lejos en separar la historia en estos compartimientos diferentes" (Almandoz, 2008, p. 247). Dividida la historia urbana de la historia del urbanismo, de la historia de la arquitectura, y luego otra vez dividida la historia social urbana de la historia cultural urbana o de la historia política urbana, el rumbo parece más desconcertante: ¿qué historia urbana?, ¿una que es poco atendida por los estudios sociales u otra encerrada en su especialización?

El ánimo principal de este texto es subrayar la importancia de la historia urbana, o -para decirlo mejor- de la perspectiva histórica en el entendimiento de la ciudad, derribando al mismo tiempo muchos muros disciplinares, conceptuales, teóricos y metodológicos que con frecuencia limitan su comprensión. Se trata, en primer lugar, de poner de relieve la necesidad de que la historia urbana recorra nuevos caminos para estudiar las ciudades del siglo xx y las de hoy, su relación con las capas superpuestas que tienen debajo, y conecte y haga explícita la realidad históricamente construida que representa la ciudad. En segunda instancia, el texto se propone mostrar algunas estrategias metodológicas útiles para el lector especializado o el principiante en la práctica de la historia urbana, las cuales, aunque conocidas, deberían ser mejor aprovechadas. En su tercera parte, el artículo ofrece una serie de propuestas, de ideas para una historia urbana capaz de derribar los muros que se han levantado, a veces por una especialización exagerada y malentendida, otras por una formación disciplinar o parcial, una más por los corsés teóricos, y no en pocas ocasiones por las inercias de la academia. El trabajo sostiene muchas de sus ideas teóricas y metodológicas en aportes historiográficos sobre ciudades mexicanas, norteamericanas, latinoamericanas y europeas. 


\section{La ciudad y la historia: derribar los muros disciplinares}

Hace más de cincuenta ańos, Herman Ausubel escribió en el prólogo a Victorian Cities, de Asa Briggs: "La gente arrogante e ignorante que cree que las dificultades urbanas del siglo xx son únicas, tiene mucho que aprender de este libro" (Briggs, 1963, p. i). Hasta entonces, 1963, las ciencias sociales llevaban varias décadas inmersas en un divorcio de hecho, levantando paredes entre disciplinas. ${ }^{1}$ Arquitectos, urbanistas, geógrafos, sociólogos y economistas habían sido poco atentos a la importancia de la historia en el estudio de la ciudad, pero los propios historiadores se habían ocupado escasamente de la ciudad por considerarla insignificante, llegando al punto de negar su existencia ontológica propia (Leidenberger, 2004, p. 54).

La reconciliación de las ciencias sociales que tuvo lugar claramente desde la década de 1960, junto con los estudios interdisciplinarios y los debates historiográficos más recientes, parecieran dar a la historia urbana un mejor ámbito de desarrollo y mejores márgenes para participar del concierto de voces sobre la ciudad. Desde entonces la historia urbana se fortaleció en muchos lugares, adquirió vigor medible, por ejemplo en la publicación de revistas especializadas como Urban History y el Journal of Urban History desde 1974, en la celebración de congresos, en la fundación de centros de estudio, y en la aparición de investigaciones sobre ciudades particulares, sobre sistemas urbanos nacionales y sobre análisis historiográficos. Se acepta como un libro clásico, y en buena medida fundador de una historia urbana renovada desde los Estados Unidos, The City in History. Its origins, its tranformation, and its prospects (Mumford, 1961), seguido en Inglaterra por el recién citado Victorian Cities (Briggs, 1963). A ellos pueden sumarse, entre muchos otros, por su representatividad, Storia della città (Benevolo, 1975), History of Urban Form. Before the Industrial Revolutions (Morris, 1979), Viena fin de siglo. Politica y cultura (Schorske, 1980), Histoire de la France urbaine (Duby, 1980-1985), The City Shaped. Urban patterns and meanings throught history (Kostof, 1998), Cities in Civilization. Culture, innovation, and urban order (Hall, 1998), y más recientemente la obra coordinada por Jean Luc-Pinol, Historia de la Europa urbana (Pinol, 2010-2012).

En el ámbito latinoamericano ocurrió otro tanto: una producción sólida desde finales de la década de 1950 que en buena medida acompaña el tono y las preocupaciones de otras latitudes: de Richard M. Morse y Jorge E. Hardoy, a Arturo Almandoz, Adrián Gorelik, Germán Mejía, Armando de Ramón y Eduardo Kingman, pasando por Alejandra Moreno Toscano, Ramón Gutiérrez, hasta José Luis Romero, el autor más influyente por su libro Latinoamérica: las ciudades y las ideas (1976).

A pesar de la relevancia de los trabajos de estos y otros muchos autores, vista en su conjunto, la subdisciplina no ha alcanzado unidad ni consolidación en América Latina. No solo en este ámbito; más en general, los historiadores no han apreciado suficientemente la necesidad de estudiar la ciudad y sus procesos en el tiempo; y las

Una interpretación de la historia del mundo, del saber en tanto una historia de divorcios, puede verse en Wallerstein (1997). 
ciencias sociales, cuando se ocupan de la ciudad, siguen ignorando en buena medida su historia. ${ }^{2}$

Las revistas de estudios urbanos dan cuenta del poco aprecio existente en América Latina por la perspectiva histórica en la disciplina, y dos medidores apuntalan esta afirmación. Uno de ellos es la bibliografía que reunió Horacio Capel (1998), una relación no exhaustiva pero indicativa de los intereses, temas, perspectivas y teorías desarrolladas en los estudios urbanos entre 1960 y 1998. Destaca la poca presencia de historiadores y de la mirada histórica en este balance, lo mismo que arroja un documento publicado por la Unesco en el cambio de siglo, titulado "La investigación urbana en América Latina. Tendencias actuales y recomendaciones" (Valladares \& Prates, s/f). Allí se revisa el desarrollo de los estudios urbanos, los temas, paradigmas, instituciones y programas en Latinoamérica a partir de la década de 1960 y, aunque se reconoce que "en los últimos decenios la comunidad de los investigadores urbanos se ha diversificado mucho", incluyendo "geógrafos, arquitectos, sociólogos, economistas, antropólogos, planificadores, historiadores y abogados", prácticamente no vuelve a haber mención alguna sobre el trabajo, los temas ni los aportes desde la historia.

Una pregunta parece flotar en el aire: ¿qué puede decir la historia o para qué vale la perspectiva histórica en los estudios urbanos, frente a los cuantiosos y difíciles apuros de las urbes contemporáneas? A veces parecen tan urgentes y tan decisivos los problemas de polución, especulación inmobiliaria, crecimientos desordenados, transporte deficiente, largas distancias, carencia de espacios y tiempos para la convivencia, baja calidad e injusticia en el acceso a las viviendas, violencia, pobreza, informalidad laboral, y tantos otros, que se han creído dificultades sin precedentes y se abordan desde una perspectiva inmediatista. Lo cierto es que la agenda urbana contemporánea por sí y las grandes transformaciones de las ciudades en el siglo xx, con sus dimensiones, alcances y rapidez, exigen múltiples esfuerzos de comprensión donde la historia ocupe un lugar de mayor relevancia en la discusión del que hasta ahora ha tenido.

En los estudios urbanos se presupone con frecuencia que los problemas de las ciudades son nuevos, que no tienen precedentes; se subestima la historia y se aprecian demasiado los modelos teóricos aplicados sin demasiados reparos. En la década de 1970 , por las facultades universitarias donde corrían las ideas marxistas, la sociología se convirtió en "la ciencia” que permitiría estudiar, entender y denunciar los grandes problemas de las ciudades, como la pobreza y la exclusión, y con ello recaía en sus manos el cambio.

De entonces hacia ahora, muchas ciudades en el mundo han experimentado condiciones que conducen a proponer con cierta ligereza que se está ante modelos nuevos de ciudad. Por supuesto, entender las dinámicas del neoliberalismo y de sus impactos urbanos es fundamental, siempre que no se pierda de vista ni la perspectiva histórica ni otras variables. 
Una fuerte corriente teórica propone que la fragmentación, los problemas sociales, los de transporte o los de la baja calidad de las viviendas son producto de los proyectos impuestos desde arriba, ya de industrialización o de vinculación con economías a escala planetaria (Harvey, 2013). ¿ ¿Son los procesos de metropolización y de cambio en la economía internacional los responsables de condiciones más marcadas de pobreza, inequidad, exclusión y problemas urbanos? Sin duda importan, pero se trata de procesos de largo plazo que, sacados de sus contextos, alejan de una comprensión del fenómeno urbano.

Michel Husson ha subrayado atinadamente que "el capitalismo tiene una historia: sus mecanismos profundos son inmutables, pero su modo de funcionamiento difiere de un periodo al otro y de un país a otro" (De Mattos, 2016, p. 34). En la misma línea, Carlos de Mattos (2016) ha añadido que las políticas neoliberales "incidieron en la generación y/o intensificación" de tendencias "constitutivas de una metamorfosis que se había iniciado con la revolución industrial” (p. 32).

Condenados por otros y a veces por ellos mismos a estudiar el pasado, los historiadores han quedado al margen de la discusión. Cuanto más, desde algunas disciplinas se recurre a la historia con una idea decimonónica, que ignora el largo camino que ha recorrido, para tomar de ella fechas y datos que se presentan como un "contexto" desvinculado de los problemas que se estudian. "La tarea del historiador -apuntó Bernard Lepetit (1992) - no es la de ofrecer a las ciencias sociales vecinas un repertorio más rico de ejemplos (...) que ellas podrían encontrar limitándose al presente (...). Por el contrario, es la exploración de los mecanismos temporales lo que puede constituir el aporte particular de la historia" (p. 32). ${ }^{3}$

Conviene subrayarlo: la historia urbana tiene mucho que aportar para el entendimiento de la ciudad actual, para buscar el sentido de sus cambios, para engarzar el presente con el pasado, para encontrar el "hilo de la trama", ${ }^{4}$ el vínculo entre dos realidades que parecen tan distantes. En este sentido, la ruta fundamental de trabajo debería consistir en romper los límites, derribar los muros disciplinares, pero también los metodológicos, temporales y espaciales, para resolver problemas más allá de las tendencias de investigación de una disciplina, para aprovechar las ventajas de las fuentes y los métodos cruzados, para evitar la estrechez de mirada que proporcionan las estadísticas y los estudios de lo inmediato.

Para que los historiadores de la ciudad participen más activamente en el concierto de los estudios urbanos hace falta superar también, desde adentro, la práctica de una historia urbana anecdótica, afinar sus presupuestos teóricos, sus objetivos, su convicción de vincular el pasado con el presente, de pensar los distintos niveles del tiempo; se hace necesario repensar sus problemas y construir operaciones metodológicas que obtengan mayor provecho del trabajo de sus fuentes.

Lo mismo se desprende de las reflexiones de Marc Augé (2007) sobre el oficio de antropólogo: por extensión, su argumento supondría que en los tiempos de la ciudad debe encontrarse su "enlace social", "cierto concepto de relaciones entre los unos y los otros en el interior de una determinada configuración cultural” (p. 32).

4 Se siguen aquí algunas reflexiones de Armando de Ramón (2000, p. 198) sobre la ciudad y la historia . 


\section{El plano y la imagen: derribar muros metodológicos y límites en el uso de fuentes}

El diálogo entre disciplinas, el giro cultural (o los giros "visual” y "espacial") y el ensanchamiento de horizontes en la práctica historiográfica han posibilitado, entre otras muchas cosas, la incorporación de nuevas fuentes y la búsqueda de caminos metodológicos para su aprovechamiento. A pesar de ello, la apertura para la explotación creativa de fuentes ha sido desigual. En historia urbana, como en la historiografía en general, por mucho tiempo los testimonios principales fueron los asociados a los documentos producidos por la administración pública.

La "nueva historia urbana” de los años sesenta ańadió un amplio número de estadísticas, pero su confianza desmedida en lo cuantitativo pasó por alto o desatendió dificultades considerables (Schnore, 1975, pp. 3-11). Entre varias más, una era su escasa confiabilidad, que no fue lo suficientemente criticada y puesta a prueba: a veces se "calzaban" las cifras a las hipótesis, como en el estudio pionero, encomiable pero insuficiente de Álvarez, Arana y Bocchiardo (1986) sobre Montevideo; otra, la dificultad para armar series, para contar con información cuantitativa levantada con los mismos criterios a lo largo de un período razonable.

El desarrollo de las ciencias sociales en las últimas décadas ha ofrecido múltiples opciones de fuentes y metodologías para la historia urbana, como los testimonios orales. Por ejemplo, el libro Metropolis, 1890-1940, de Anthony Sutcliffe, publicado en 1984, ayudó -según Arturo Almandoz (2002)_ "a establecer que el entendimiento del concepto histórico de esa forma urbana, al menos para el período de la modernidad industrial, pasaba por la revisión de su arquitectura, artes visuales, música, cine, literatura y vida intelectual en general” (p. 34).

Cualquier revisión a los trabajos de historia urbana producidos en diversos ámbitos académicos desde la década de 1980 evidencia sin duda la creciente diversificación de las fuentes utilizadas, aunque el grado de pericia con que se analizan sigue siendo variable. Las imágenes son cada vez menos simples ilustraciones, los mapas han pasado de los anexos al cuerpo de la argumentación, pero una historia urbana más abierta (lo mismo que la historia y las ciencias sociales en general) exige incorporar más y mejores fuentes, de la mano de las discusiones y propuestas generadas en otras disciplinas.

El abanico de posibilidades es casi ilimitado: desde el fundamental documento público producido por los distintos niveles de la administración, incluyendo las escrituras notariales, pero también la prensa, las revistas especializadas, los archivos de las empresas de servicios, las estadísticas, la historia oral, la literatura (poesía, ensayo, novela, relatos de viajeros), y todos los productos culturales: de la música a la litografía, de la fotografía al cine, de las obras de teatro a las guías de turistas o de la cartografía a las artes plásticas.

Además del uso de fuentes valiosas, entendidas como testimonios culturales y analizadas con nuevas miradas, debe subrayarse la necesidad de construir corpus documentales "de segundo nivel", es decir, fuentes armadas de acuerdo con los objetivos planteados por el investigador. Por ejemplo, los directorios telefónicos pueden no solo mostrar las huellas de personas, profesionistas, comercios, servicios o 
productos, sino dar suficientes informes para enriquecer bases de datos más amplias. De la misma manera, los árboles genealógicos y los diagramas de redes ofrecen una ventana poderosa para entender el papel de las elites en una ciudad, los mecanismos de articulación y de operación de los agentes.

\section{El mapa}

En el conjunto abundante de fuentes posibles se quiere destacar aquí los mapas y las imágenes. El dominio de la historia social y cultural de las últimas décadas ha tendido a invisibilizar los resortes económicos y ha reducido considerablemente en los libros de historia las gráficas, las estadísticas y, aún más, el papel de los agentes económicos, la problematización del valor de la tierra, entre otras. Detrás podría haber un interés por facilitar la lectura y el entendimiento de los procesos, no abrumando al lector con tablas llenas de cifras oscuras, pero también una falta de pericia de muchos historiadores para trabajar con números. Algo similar ocurre ante la posibilidad de enfrentar y aprovechar las imágenes y los planos.

Hace no mucho, J. B. Harley (2006) se preguntaba por qué han recibido tanto desprecio los mapas en la investigación social e histórica. "Cuando un historiador toma un mapa -escribió-, por lo general lo hace para responder alguna pregunta relativamente limitada acerca de la ubicación o la topografía...” (pp. 59-60). Evidentemente, la ciudad y el plano son inseparables, la representación cartográfica es una de las expresiones clave del fenómeno urbano, pero ocurre que tradicionalmente los libros de historia de las ciudades han ido magramente acompañados de planos, negando esa posibilidad básica de revisar, imaginar y explicar la ciudad en su dimensión espacial.

La Historia de la Europa urbana (Pinol, 2010-2012), uno de los esfuerzos recientes más acabados de la historia urbana, que reúne en sus seis tomos a los historiadores europeos más destacados en la materia, llama la atención por la escasa presencia de imágenes y mapas. Sobre estos, se incluyen dos series bien pensadas para la obra en conjunto, una de las cuales muestra las sesenta principales ciudades europeas en cinco momentos consecutivos $(1500,1600,1700,1750,1800)$. Ciertamente se trata de visiones generales y por ello la cartografía se centra en mapas que ubican las características del sistema urbano europeo, pero no dejan de extrañarse los planos individuales y comparativos de las ciudades y sus procesos en el largo curso de los siglos.

Es cierto que el uso de los mapas como documento para la historia de las ciudades no es nuevo; incluso puede notarse un uso relativamente abundante en la última década, generado en parte por la influencia de los arquitectos y los geógrafos. Jordana Dym (2010) ha mostrado la trayectoria de una "revolución en los estudios cartográficos" impulsada por la historia del arte, la ciencia política, la literatura y la geografía, para evaluar esta fuente "como artefacto cultural" (p. 102). Sin embargo, su balance específico sobre los planos urbanos es limitado en dos sentidos: por una parte, por los pocos ejemplos que muestra; y por otra, debido a su interés en el aprovechamiento de los mapas antiguos más bien como objeto de estudio que como fuente. 
El trabajo con los mapas desde la historia y desde la historia urbana requiere múltiples precauciones, y aunque no es el objetivo ahondar aquí en rutas metodológicas conocidas, sí conviene hacer algunas anotaciones al respecto, ampliando las nociones sobre el trabajo cartográfico. ${ }^{5}$

Hay que comenzar con una distinción elemental entre tres tipos de mapas útiles para la investigación social: 1) los mapas antiguos, es decir, los que fueron formados en un contexto y con reglas de producción específicas y que han sobrevivido; 2) los mapas contemporáneos, que suelen ser útiles para comparar, para ubicar los rastros de los espacios del pasado en los espacios presentes, incluyendo las herramientas de análisis espacial que se desarrollan, por ejemplo, por Google; $\left.{ }^{6} 3\right)$ los mapas construidos, la cartografía temática formada por los propios historiadores en función de sus necesidades de investigación.

En el primer caso importa principalmente una lectura crítica y que entienda el lugar y práctica de producción. Un plano de Cuzco, publicado en 1556, puede ser un buen ejemplo (figura 1). Bien analizado, para el investigador puede resultar decepcionante corroborar que la traza, la composición y el panorama general de este plano corresponde a una imagen ideal y no a una "real". Apareció por primera vez en el tercer volumen de la obra de Ramusio, Viaggi et Navegationi, en Venecia. $\mathrm{Al}$ analizarlo se le llegó a calificar como un "capricho", pues en el grabado aparecen murallas que recuerdan las ciudades medievales, un gran templo ceremonial inca que para entonces había sido destruido, y una serie de elementos adicionales que poco reflejaban la apariencia de la ciudad (Kagan, 2000, pp. 69-70).

El plano de Ramusio, dice Richard Kagan (2000), "pertenece a una tradición establecida de vistas europeas que privilegiaban el simbolismo sobre la realidad, la geografía moralizante sobre la cartografía científica” (pp. 69-70). Se trataba, en principio, de mostrar que Cuzco era "una ciudad imperial, la capital de un reino similar a aquellos con los que los europeos estaban familiarizados". Esta idea iconográfica se mantuvo por mucho tiempo; de hecho, señala Kagan, el plano fue reproducido muchas veces más durante los siglos XVI y XVII, añadiéndose elementos extravagantes con la introducción de variantes y haciendo parecer que la ciudad estaba detenida en el tiempo (pp. 95-101; figuras 2 y 3).

Estos y otros resultados fueron publicados por Kagan en el ańo 2000, en uno de esos libros que comenzaron a entender en un sentido más amplio los planos urbanos de Hispanoamérica como artefactos culturales, superando trabajos previos y loables que habían sido más dirigidos a la compilación cartográfica. ${ }^{7}$

5 El estudio de los mapas y su importancia ha sido subrayado en los últimos ańos por muchos autores, aunque sigue siendo Harley una referencia muy recurrida en los ámbitos académicos. Puede verse complementariamente, sobre Iberoamérica, Jordana Dym y Karl Offen (2011), y los productos de los congresos iberoamericanos de historia de la cartografía; y a nivel general, The History of Carthography (1987-2007).

6 El uso de Google Earth ha sido ponderado y aprovechado, por ejemplo, en la revista ar@cne, desde el año 2007; pueden verse varios artículos en http://www.ub.edu/geocrit/aracne.htm

7 Quizá uno de los primeros esfuerzos iberoamericanos es el de Torres, Chueca y González (1951). Jorge Hardoy hizo una recopilación importante de cartografía urbana colonial de América Latina y el Caribe, en Cartografía... (1991). 


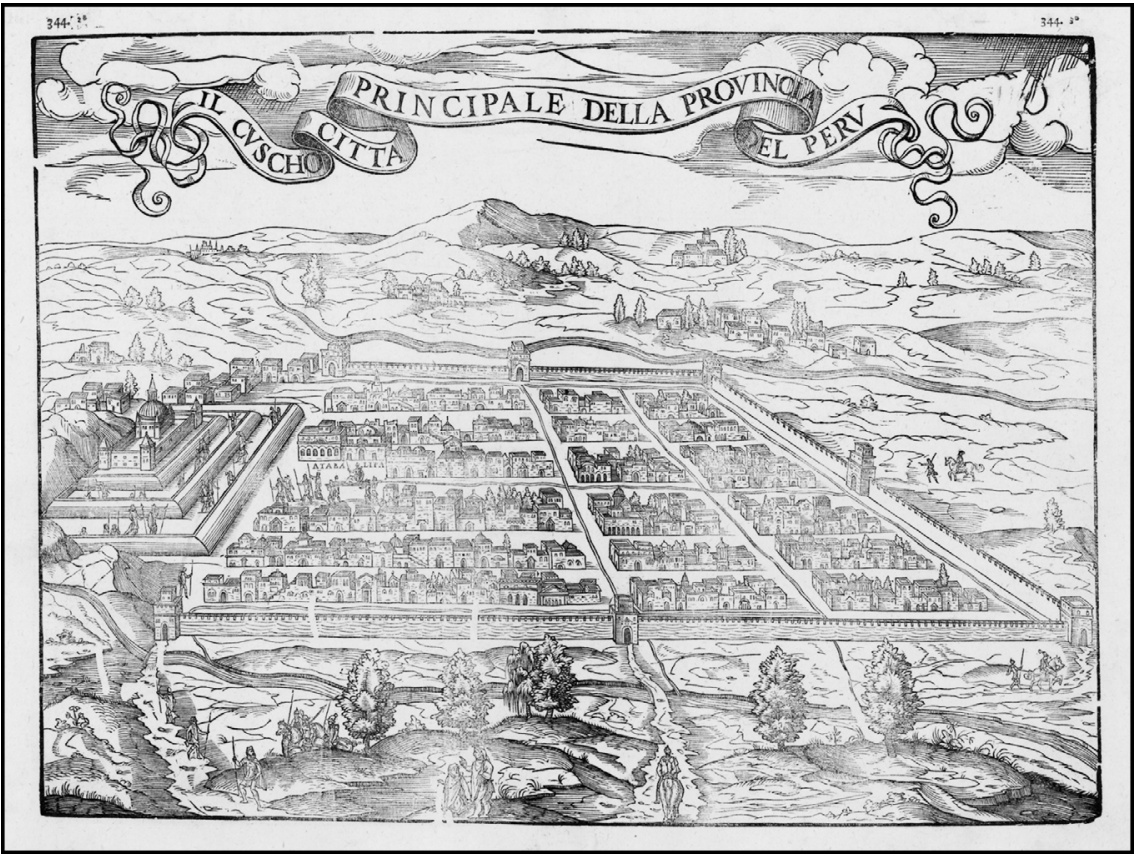

FIGURA I | Planos históricos de Cuzco con representaciones ideales y ajustadas caprichosamente: 1556

FUENTE: TOMADA DE KAGAN (2000)
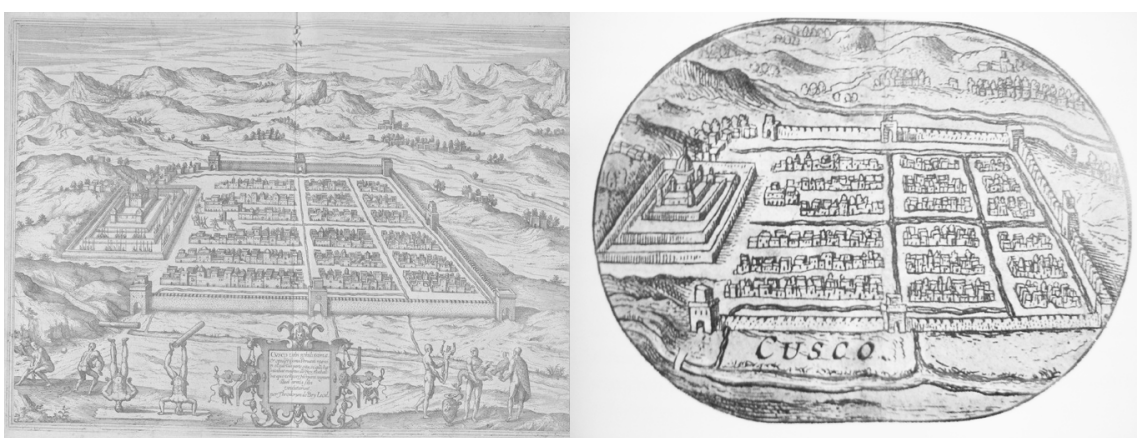

FIgURA 2 Y 3 | Planos históricos de Cuzco con representaciones ideales y ajustadas caprichosamente: 1596 y 1645

FUENTE: TOMADA DE KAGAN (2000)

La construcción de cartografía es, por otra parte, una herramienta poderosa para el investigador, tan amplia como su capacidad de imaginar, como su aporte de creatividad para identificar fuentes, convertir datos en recursos susceptibles de ser expresados en mapas y analizar problemas en su dimensión espacial. En esa construcción, el plano antiguo y el plano histórico (temático) dialogan y aportan información de ida y vuelta. La construcción de mapas temáticos en la historia urbana en México se 
ubica al menos desde la década de 1970, en estudios sobre la propiedad urbana y los usos de suelo. ${ }^{8}$ Otros más recientes han permitido pensar las ciudades en su conjunto. ${ }^{9}$

Un ejemplo de la construcción de cartografía para el estudio de procesos históricos urbanos es el realizado en torno a una ciudad mexicana de los primeros años del siglo $\mathrm{xx}$, interesado en identificar las zonas menos conocidas, "la ciudad invisible", los barrios marginales y sus formas de habitarlos, las problemáticas sociales, los vicios y la persecución del delito. Los datos arrojados por documentos judiciales, notas de prensa, estadísticas, reglamentos y diversos padrones, permitieron elaborar una serie de planos cuya lectura proporciona interpretaciones más ricas, distintas y complementarias que las otorgadas por los documentos antes de ser traducidos al lenguaje cartográfico. Un primer ejercicio consistió en colocar en un plano la ubicación de las poco más de 200 vecindades enlistadas por los inspectores de la ciudad (figura 4).${ }^{10}$ Entre las muchas lecturas posibles, el ejercicio llama la atención sobre la alta presencia de estas formas de habitación (asociadas casi siempre a algún grado de pobreza y otro de hacinamiento), sobre su casi nula existencia en las cuadras inmediatas a la plaza principal (reservadas para las viviendas de la elite), o sobre el grupo más numeroso que se aprecia en el noroeste, evidenciando el lugar de habitación de muchos obreros que llegaron a trabajar a la Fundición Central Mexicana.

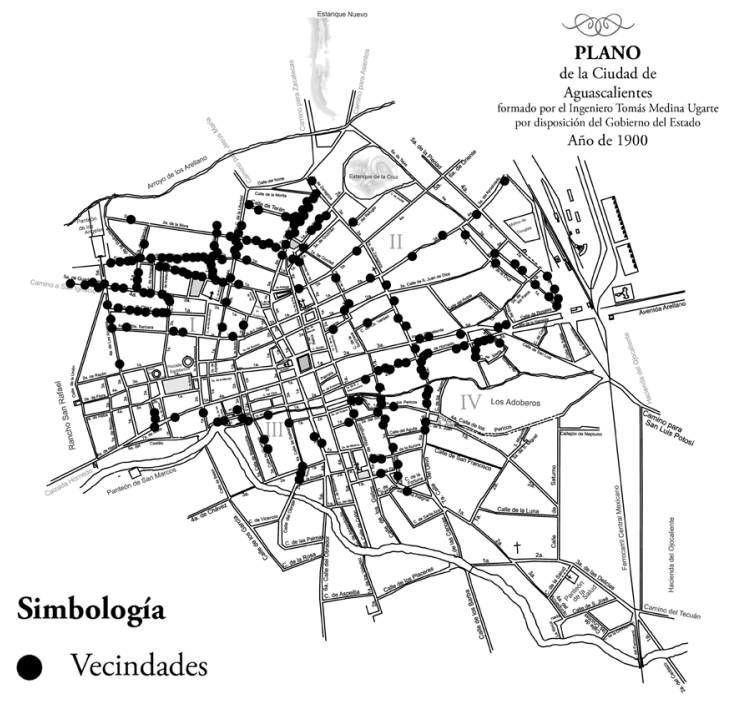

FIgUra 4 | Vecindades en la ciudad de Aguascalientes hacia 1910

FUENTE: ELABORACIÓN PROPIA CON BASE EN PLANO DE LA CIUDAD DE AGUASCALIENTES, DE TOMÁS MEDINA UGARTE (I 9OO), CON INFORMACIÓN SISTEMATIZADA DE LAS LISTAS DE VECINDADES LEVANTADAS EN LAS CUATRO DEMARCACIONES DE LA CIUDAD EN I9I7 Y CON INFORMES DE DIVERSOS EXPEDIENTES JUDICIALES

8 Pueden verse los trabajos de María Dolores Morales; entre ellos, Morales y Gayón (2001).

9 Por ejemplo, los mapas agrupados en las 53 láminas de la Sección de Historia, coordinada por Héctor Mendoza Vargas, del Nuevo Atlas Nacional de México (Coll, 2007).

10 Archivo Municipal de Aguascalientes, Fondo Histórico, Exp. 443.39 y datos complementarios tomados de referencias aisladas encontradas en diversos expedientes de la serie Judicial Penal, 1874-1914, resguardados en la Casa de la Cultura Jurídica de Aguascalientes. 
El trabajo consideró un conjunto amplio de fuentes complementarias para lograr entender la ciudad más allá de ese "cinturón" de vecindades que rodeaba al centro. Uno de estos planos reconstruye los recorridos asignados a cada uno de los casi cien policías que tenían a su cargo el orden de la población (figura 5). La serie cartográfica puede leerse de manera individual o comparativa. Llama la atención, por ejemplo, descubrir en este plano los extremos de la ciudad, en los cuales no había policía designado, donde la administración municipal cedía su poder, seguramente incapaz de ejercerlo: una conclusión que difícilmente podría tenerse con la información proporcionada por las fuentes antes de su traducción, de su reconstrucción sobre el espacio.

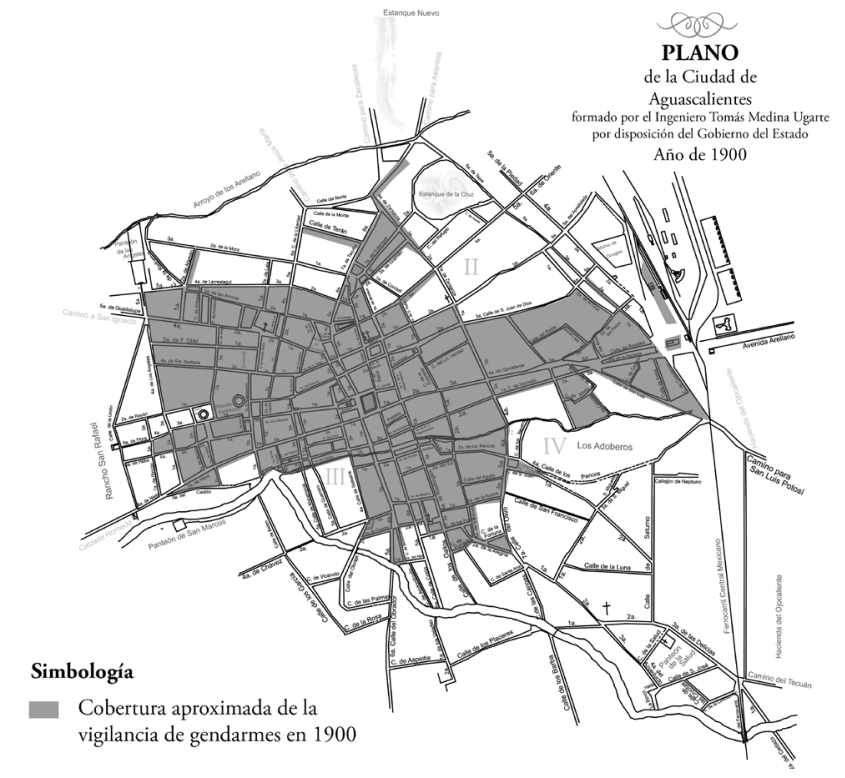

FIgURA 5 | Cobertura de seguridad pública en Aguascalientes hacia 1900. Sobre el plano se marca el polígono de cobertura de seguridad en la ciudad, a partir de la identificación de las rutas de los gendarmes. Nótense las áreas blancas, donde la presencia policíaca no llegaba.

FUENTE: ELABORACIÓN PROPIA CON BASE EN PLANO DE LA CIUDAD DE AGUASCALIENTES, DE TOMÁS MEDINA UGARTE (I 9O0), CON INFORMACIÓN SISTEMATIZADA DE LA "LISTA DE LOS GENDARMES QUE HAY EN LAS DEMARCACIONES", ELABORADA EN I900: ARCHIVO MUNICIPAL DE AGUASCALIENTES, FONDO HISTÓRICO, EXP. 258.3

En los estudios urbanos que centran sus desvelos en los problemas inmediatos, los Sistemas de Información Geográfica (SIG) han evidenciado su enorme potencialidad y han sido aprovechados ampliamente. Quizá haya que señalar los posibles abusos a los que puede conducir la confianza excesiva en ellos, como en otro tiempo ocurrió con la apuesta tan alta que se puso sobre las posibilidades de lo cuantitativo. Lo cierto es que en el campo de la historia urbana han sido mucho menos explotados los SIG, en buena medida por las dificultades propias que impone contar con la materia prima, pero también por falta de pericia del historiador. 
La figura 6 ofrece, desde una lectura a otra escala (regional), algunas respuestas sobre el papel desempeñado por la misma ciudad -Aguascalientes- a finales del siglo XIX. Aprovechando los registros de los mesones, que dan cuenta de las entradas de arrieros, su procedencia y a veces el tipo y número de cargas, el mapa expresa el origen e intensidad de los flujos de cargas agrícolas que entraban a la ciudad a lomo de mula a finales del siglo xix (Martínez, 2017). Esta herramienta no solo traslada un legajo extenso con datos poco llamativos a una imagen; más importante, ayuda a dimensionar las relaciones que el núcleo urbano central establece con su región, su lugar como centro de mercado, y aún más, señala con un buen grado de exactitud la región económica de la que era centro la ciudad, lo cual puede corroborarse con planos complementarios y con preguntas y fuentes adicionales.

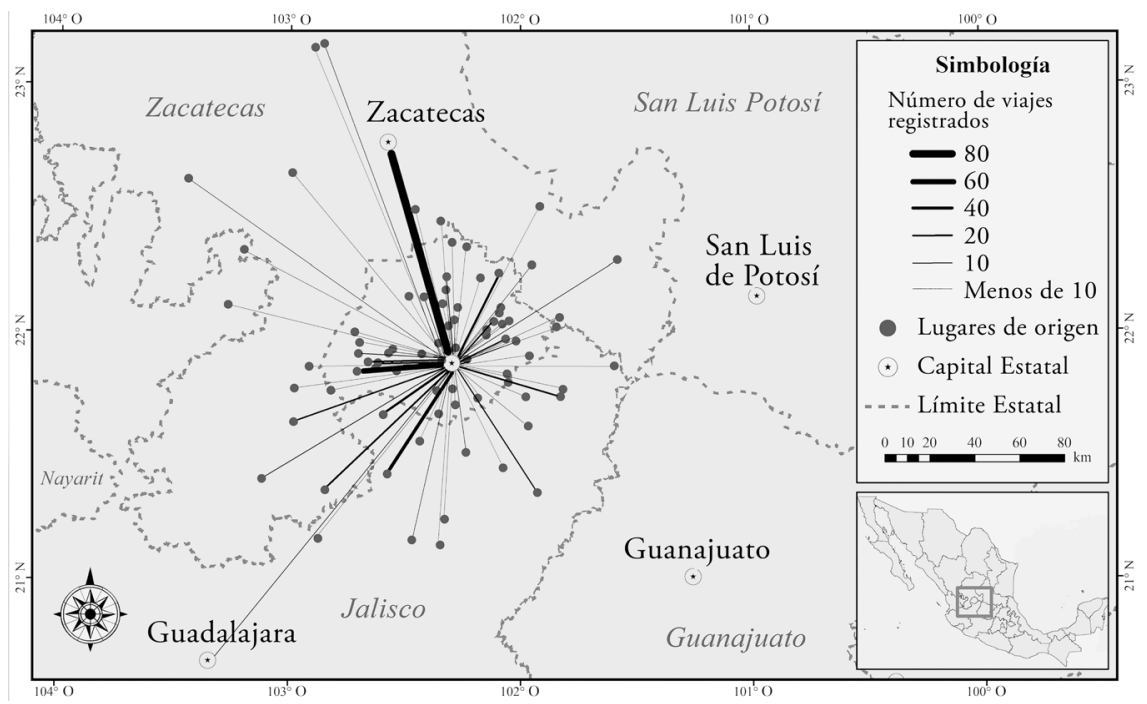

FIgURA 6 | Lugares de origen e intensidad de flujos de productos agropecuarios conducidos por arrieros a la ciudad de Aguascalientes a finales del siglo XIX

FUENTE: ELABORACIÓN PROPIA CON BASE EN LA TABLA DE DATOS CONSTRUIDA CON UNA MUESTRA DE REPORTES DE INGRESO A MESONES, AÑO I 884, ARCHIVO MUNICIPAL DE AGUASCALIENTES, FONDO HISTÓRICO, EXP. I 5.I 7. DISEÑO: JORDI PRAT

En algunas ocasiones, la existencia de una buena serie de mapas antiguos y los problemas que les puede plantear la historia urbana permiten articular una investigación teniéndolos como fuente vertebral e hilo conductor del análisis. Muchas ciudades pequeńas o grandes cuentan con series importantes, al menos para los siglos XIX y xx. Como se ha dicho, desde hace algunas décadas, geógrafos e historiadores han reparado en la importancia de los mapas históricos; a veces han reunido atlas, otras han aprovechado la cartografía para ubicar sitios, pero el ensanchamiento al diálogo disciplinar, los análisis detallados y el uso de nuevas fuentes supone esfuerzos adicionales, al aprovecharlas e interrogarlas con más diligencia para plantear preguntas y obtener respuestas distintas. 


\section{Imágenes}

El uso de imágenes en ciencias sociales, en historia y en historia urbana es otro campo de resistencia para muchos investigadores. Su uso se mostró fecundo con los intercambios habidos entre la historia y los estudios del arte, la filosofía, la semiología o la teoría de la imagen. Un llamado bien conocido en múltiples ámbitos académicos es el de Peter Burke (2001), aunque -como en otros casos- el trabajo con imágenes era mucho más viejo, pero menos sistemático. Desde la historia del arte, Michael Baxandall (1978) había subrayado ya en la década de 1970 que "buena parte de la experiencia más importante no puede ser cómodamente codificada en palabras y números" (p. 186).

La investigación histórica sobre las ciudades de los últimos 180 años tiene en la fotografía una de sus fuentes más extraordinarias, pero cierta impericia metodológica ha replegado, o al menos limitado, los esfuerzos también en este campo. Quizá la duda inicial sobre qué registran, para qué nos sirven, qué tan confiables son, cómo analizarlas y aprovecharlas dentro de la investigación histórica, ha sido un obstáculo teórico que debería aprovechar con más apertura los caminos andados.

Uno de los libros pioneros que estudiaron la ciudad a partir de la fotografía fue Silver Cities: Photographing American Urbanization, 1839-1939 (1984), de Peter Bacon Hales, un historiador del arte que entrelaza finamente la técnica, los formatos, los intereses de fotógrafos y editores, y los procesos urbanos de las ciudades estadounidenses. Bacon propuso una periodización de las dinámicas urbanas estadounidenses de un siglo entero y encontró correspondencias con el tipo de trabajo que hicieron los fotógrafos en ellas. Esta relación dialéctica ciudad-fotógrafo está siempre presente en su texto, pero también otros tipos de estrategias metodológicas que le permitieron analizar las imágenes. Identificó, por ejemplo, las fotografías que hacia el cambio de siglo querían ponderar el vigor, la energía y orden de ciudades como Chicago o Nueva York, pero también las que mostraban el caos, el tráfico, la inseguridad.

Es curioso, pero fue también en 1984, el mismo año en que Anthony Sutcliffe publicó Metropolis y Bacon, Silver Cities, cuando Patricio Gross y Armando de Ramón publicaron Imagen ambiental de Santiago 1880-1930, un libro con el que quisieron "ensayar un procedimiento que nos permita otorgar a la imagen gráfica una importancia mayor de la que hasta ahora le ha sido concedida” (pp. 13-14). Su búsqueda fue importante, pero a la distancia muestra sus limitaciones. Su método consistió en fechar las fotografías, agruparlas, seleccionarlas, y aplicarles una "crítica de fuente". Al final, no obstante, el trabajo fue apenas preliminar, porque esas fotografías, seleccionadas "de manera que su mensaje sea fácilmente legible" (Gross \& De Ramón, 1984, pp. 13-14) y ordenadas de forma temporal o espacial, sirvió solamente para acompañar sus textos construidos de manera independiente y con otras fuentes.

Sin duda, en los últimos treinta años la fotografía ha ganado mucha notoriedad en la historia urbana, casi siempre bajo el influjo de la historia cultural. Pero como las imágenes tienen un poderoso atractivo que las acerca al estatus de fetiche, y como recientemente se ha descubierto o revalorado un gran número de ellas, tienden a utilizarse masivamente, sin criterio. Si no se incorporan a un discurso historiográfico, 
si se quedan en su estudio particular, o si se olvida su necesario cruce con otras fuentes, se corre el riesgo de que vuelvan a su condición de simples ilustraciones.

Como se ha mostrado en otro texto (Martínez, 2007), el aprovechamiento de imágenes para la historia urbana debe pasar por una serie de pasos metodológicos. En una primera etapa, para identificar situaciones, fechar al menos de forma aproximada, ordenar y clasificar, a veces mediante una base de datos que permita crear más de una etiqueta para cada imagen. El segundo paso debe consistir en la crítica de fuentes, como en cualquier otro documento, poniendo especial énfasis en entender el lugar y la práctica de producción: el fotógrafo, su equipo, sus dificultades y posibilidades técnicas, sus trucos, sus enfoques, el soporte físico y sus huellas, el lugar en que se produce, las posibles razones de su elaboración, y la historia de su circulación. Como esta ruta suele ensanchar demasiado el trabajo muchos historiadores procuran evitarla, sin ser del todo conscientes de la debilidad explicativa a que se orillan. Al contrario, a partir de ahí el análisis debe continuar, hacerse más fino, por ejemplo con un ejercicio para ubicar el espacio retratado en el corpus fotográfico de una ciudad: cartografiar para entender qué de la ciudad se retrata, cuáles son las posibilidades de imaginar lo visto y lo no visto.

Aún más, el nivel más particular implica pasar del conjunto a cada fotografía (o a una selección de ellas) para hacer una descripción, una lista de objetos o situaciones que aparecen, interpretar las posibles intenciones del autor, identificar lugares y contextualizar. Otra vez, como en el tratamiento de cualquier fuente, el análisis fotográfico requiere del apoyo, en todas sus etapas, de las fuentes alternas, ya para ubicar un modelo de automóvil, el letrero de un comercio, o ya para buscar la manera en que se reflejan y se corresponden las imágenes visuales y las imágenes narradas, en que se conectan las ideas, anhelos, proyectos y visualizaciones de una ciudad.

En 1904, la compañía Underwood \& Underwood puso a la venta una colección titulada "Tour de los Mormones", con 29 fotografías estereoscópicas relacionadas con la ciudad de Salt Lake City. Richard Neitzel Holzapfel (1992), autor de un análisis cuidadoso del set y de las imágenes en lo individual, describe así una estereoscópica de la colección (figura 7):

... una escena urbana de la cual podría sentirse orgullosa cualquier ciudad americana de la época. La vista muestra cosas modernas, los tranvías eléctricos, los edificios comerciales, postes de teléfono y electricidad, calle pavimentada, hombres en trajes de negocios, mujeres a la moda, y el edificio del Salt Lake Herald (...). La calle está inusualmente limpia. (p. 171)

Interesa destacar la descripción, una entre muchas otras posibles, una lectura idónea para explorar una parte de esa ciudad norteamericana en los albores del siglo xx. Importa también, más allá, destacar el trabajo de Neitzel, quien tuvo a la vista la historia de la empresa de los hermanos Underwood, revisó sus posibilidades técnicas y de reproducción de imágenes, el perfil de sus fotógrafos, los resortes y la dinámica económica de la firma. Al revisar la serie, descubrió que, a excepción de dos, los edificios eclesiásticos de la ciudad no fueron incluidos, pero sí la Court House-City, por ejemplo. 
Apoyado en el ejercicio amplio de interpretación, el autor afirmó que, a través de este set, y de otros producidos por la misma empresa, se quería transmitir y reproducir los valores de las clases medias blancas americanas. Hasta muy poco tiempo atrás, las imágenes dominantes de los mormones habían sido peyorativas; eran siempre mostrados como fanáticos, ignorantes y polígamos. Estas imágenes mostraban, en cambio, que la religión había logrado transformarse "por las instituciones educativas y democráticas americanas”. Si Salt Lake City había sido en el siglo xix fundamentalmente una ciudad árida, desolada, ahora aparecía, según el texto que acompańaba una de las imágenes, como una ciudad con "excelente equipamiento moderno, como agua, gas y electricidad", era "un importante centro de comercio"; el desierto, apunta el autor, "había sido redimido por la moderna tecnología” (Holzapfel, 1992, pp. 169-170). Un texto como este, al analizar los encuadres seleccionados intencionalmente por los fotógrafos o sus editores, descubre las ideas que se quería trasmitir sobre una ciudad, no solo los lugares, situaciones, mobiliario, servicios y gente viviendo y construyendo la ciudad.

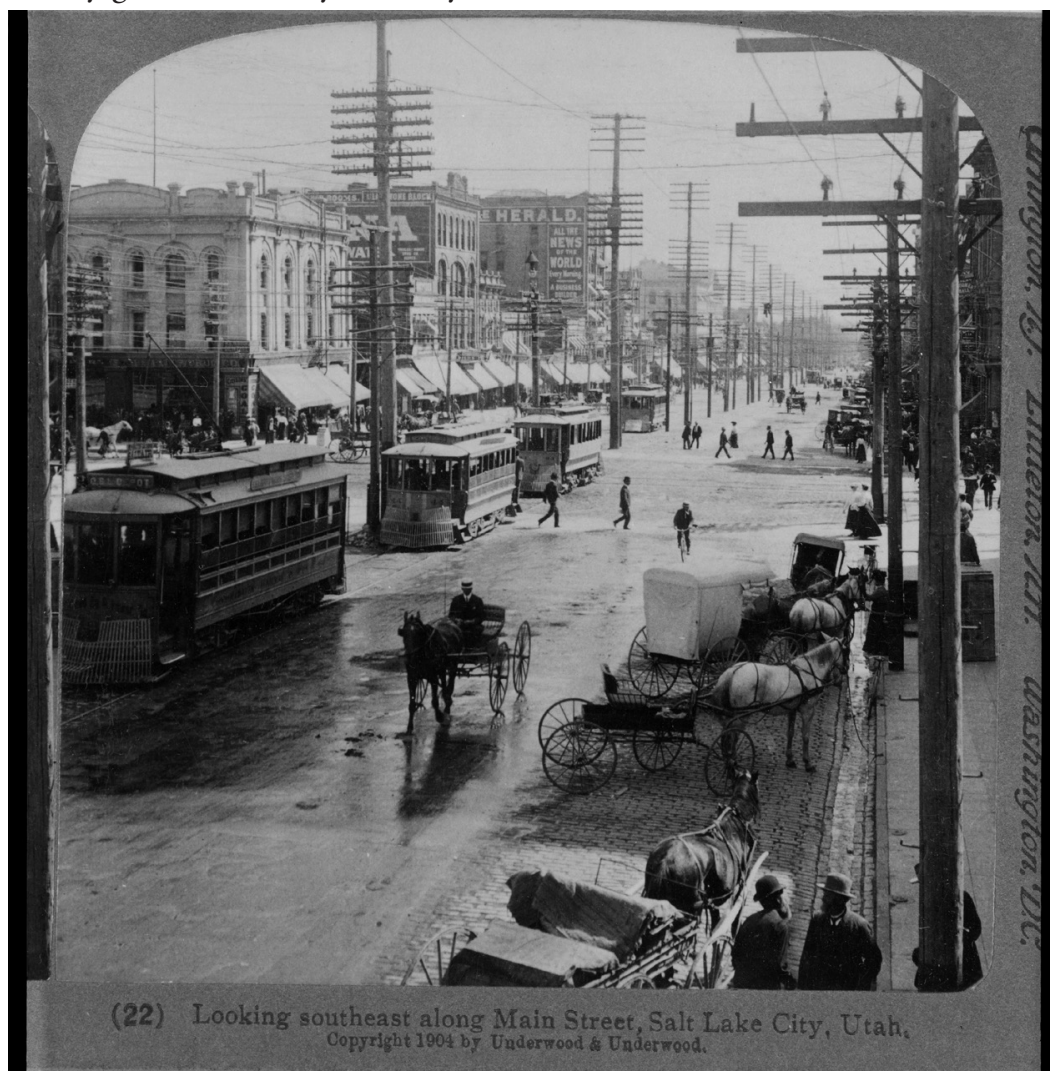

FIGURA 7 | "Looking southeast along Main Street, Salt Lake City, Utah”. Álbum de la firma Underwood \& Underwood, publicado en 1904, analizada en Holzapfel (1992), p. 171.

FUENTE: LIBRARY OF CONGRESS PRINTS AND PHOTOGRAPHS DIVISION WASHINGTON, D.C., LC-USZ62-70595 
Ante todo, las fotografías son una herramienta poderosa para pensar el cambio urbano. En Bogotá, un álbum publicado en 1938 hizo parte del trabajo de un historiador: comparó dos fotografías tomadas a la misma calle, con el mismo ángulo pero con treinta ańos de distancia (figura 8). El resultado, al menos en una primera lectura, puede ser asombroso: la ciudad, o más bien esa calle, parecen haberse detenido en el tiempo. Desde luego, esa conclusión fácil es insuficiente, pero puede ser el principio de un estudio mucho más detallado, guiado por la duda, por las inquietudes despertadas por una comparación fotográfica.
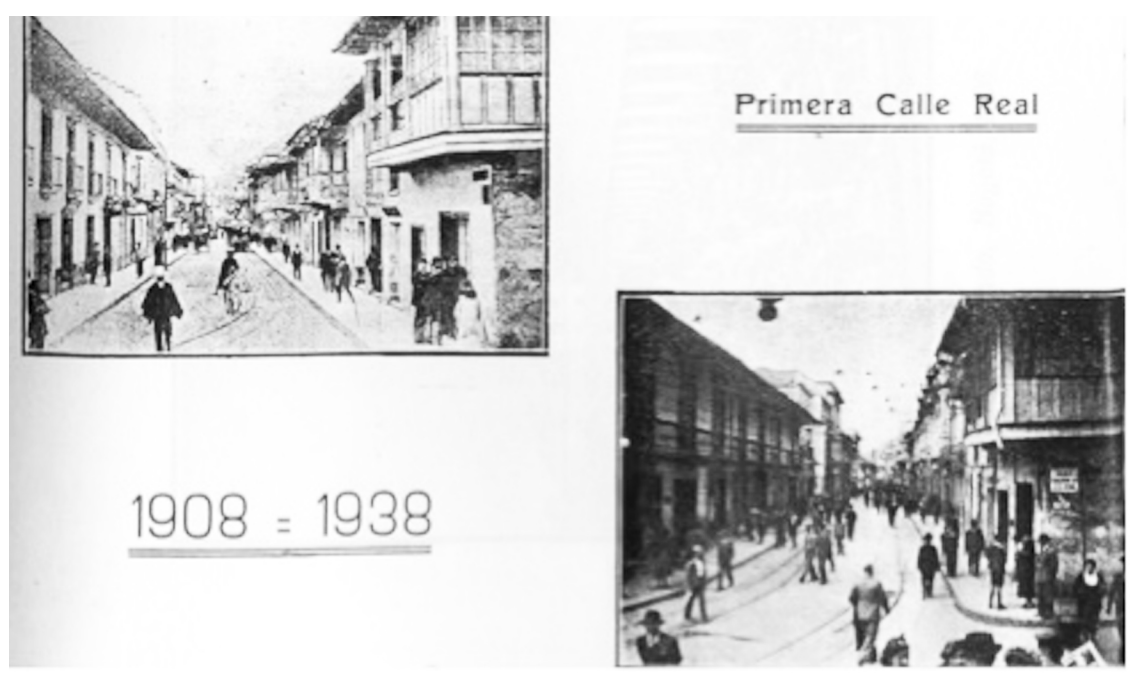

Figura 8 | Álbum de Bogotá. Publicado con motivo del cuarto centenario de fundación de la ciudad.

FUENTE: FOTOGRAFÍA CORTESÍA DE GERMÁN MEJÍA PAVONY

La fotografía y la ciudad, como compañeras desde hace casi dos siglos, ofrecen posibilidades infinitas a la historia urbana en sus múltiples formatos. ${ }^{11}$ Ciertamente, planos e imágenes son fuentes más idóneas para los estudios que se enfocan en los últimos 170 o 200 años, pero no les son extrañas a otros períodos, y armar series es una ruta metodológica de primer orden para buscar un "engarce" entre épocas. Si las estadísticas han mostrado sus dificultades para armar series, quizá puede ser más sencillo en el estudio de ciudades formar grupos seriados de cartografía e imágenes.

11 Desde fuera de la historia puede verse el texto de Gillian Rose (2014), "Visual Culture, Photography, and the Urban. An interpretative framework", Space and Culture, India, p. 4-13. Un libro para Centroamérica es el de Quesada (2011). Para el caso de México, puede verse Lourdes Roca (2011) y Eulalia Ribera y Fernando Aguayo (2014). 


\section{Historia urbana y estudios urbanos con perspectiva histórica: derribar las etiquetas y ampliar los horizontes teóricos pensando la ciudad como problema}

Una de las lecciones más perdurables de los historiadores reunidos en torno a la revista francesa Annales, que ha cruzado las preocupaciones de todas sus generaciones, ha sido pugnar por la historia problema, es decir, entender la formulación de preguntas como un punto de partida elemental del historiador. En su origen, se quería superar las historias descriptivas, aquellas apegadas a los documentos, para interrogar con creatividad a las fuentes, para partir de problemas sugeridos por el tiempo del historiador, por sus desvelos en el presente. Al plantear preguntas originales, renunciando a los estrechos márgenes que imponen las disciplinas y las teorías de moda seguidas al pie de la letra, la historia en general, y la historia urbana en particular, quedan abiertas a la comparación, a la pluralidad de perspectivas.

Plantear un problema ante una ciudad que se estudia en términos históricos supone hacer a un lado cierta rigidez de la "historia cultural" o la "historia social", para entender los resortes económicos o políticos, junto a los sociales y culturales; derribar los falsos límites entre la historia urbana y la historia urbanística o la historia de la arquitectura. Esto mismo permite pensar con más libertad el uso de fuentes, recurrir a una multiplicidad de testimonios susceptibles de ser cruzados, lo que potencializa las ideas y la capacidad de entender los procesos que se estudian.

Además de todo lo anterior, partir de preguntas y no de modelos canónicos implica derribar una serie de muros teóricos y empíricos, para generar espacios abiertos donde la historia urbana, y los estudios urbanos con perspectiva histórica, sean campos más cercanos. Frente a múltiples limitantes, no sobra plantear investigaciones que sean conscientes de algunas prisiones en las que han sido encerradas; promover estudios:

1. Que no pierdan de vista ni la urbs (lo físico), ni el civitas (las formas de vida) ni la polis (la organización política); que no se limiten a una de esta dimensiones. Los arquitectos y urbanistas hace tiempo saben que detrás de las calles y los edificios hay ideas, personas e historia. La historia de la arquitectura, la del urbanismo y la de la planificación no necesariamente debe desligarse de la población, de las formas de vida, ni tampoco de la organización política y la administración.

2. Que no se pierdan en las olas de la historia social y cultural, es decir, que sean atentos a las dimensiones territoriales (a la geografía), que entiendan la dimensión política, y que valoren y dialoguen con la economía, que derriben los límites de la especialización.

3. Que derriben los muros entre la ciudad y el campo, es decir, que valoren el hinterland y las relaciones que toda ciudad debe establecer con el exterior. Tal vez en busca de su individualidad, de su existencia ontológica propia, los estudiosos urbanos se apoyaron en la vieja idea de división entre el campo y la ciudad, que se han querido entender como dos realidades distintas, cuando no opuestas. Al incorporar a los estudios de ciudad lo que ocurre en el campo inmediato, y a 
veces lejano, se posibilita dimensionar mejor el papel de la ciudad. El estudio del abasto alimenticio, por ejemplo, es una ruta alternativa interesante para correr el velo y mejorar la comprensión de una ciudad, los mecanismos que ponen en juego para garantizar su funcionamiento y su relación con otras dimensiones territoriales (Martínez, 2017).

4. Que tengan en cuenta los imaginarios: las ideas y los proyectos son a veces tan importantes como eso que alguna vez se pretendió sobre la verdad, lo que ocurrió sobre la ciudad. La literatura, como el arte y la fotografía, como los planos y los planes, dicen algo sobre la ciudad que fue, pero mucho más sobre la ciudad que alguien vio, sintió, vivió, anheló, añoró.

5. Con períodos distintos a los de la historia política, económica o social. Una de las pruebas de que la ciudad puede ser un objeto de estudio propio la otorgan sus tiempos particulares. Los tiempos de las ciudades no son los tiempos políticos, sus cambios no se deben solo a la decisión o a la acción de un gobernante, ni siquiera de aquellos que cubren largos períodos; las ciudades inglesas del siglo XIX no asocian sus revolucionarios cambios a la acción de la reina Victoria.

6. La historia urbana ha sido en muchos momentos una historia de los espacios de sus elites. En algunos momentos, sobre todo desde la segunda mitad del siglo XIX, los barrios marginales fueron objeto de estudio de las instituciones y atractivo para periodistas, quienes dejaron imágenes narradas o visuales de esos mundos urbanos. No obstante, algunos períodos de la historia de las ciudades obligan al investigador a hacer un esfuerzo adicional por entenderlas en su conjunto, con sus áreas centrales y sus espacios periféricos, incluso con sus zonas que equivocadamente han sido calificadas como rurales, cuando han pertenecido claramente a las ciudades.

7. Que pongan a dialogar a las grandes ciudades con las medianas y pequeñas. En casi todos los ámbitos académicos, pero quizá marcadamente en el latinoamericano, las ciudades que han merecido ser historiadas han sido limitadas: las capitales, los grandes puertos, los casos más espectaculares de industrialización o de crecimiento (Romero, 1999). Desde la década de 1990 se han multiplicado los estudios de ciudades medianas, los que deberían renovarse, consolidarse e integrarse, para superar de una vez ciertos estereotipos que se han repetido sobre las "transformaciones radicales" de las ciudades "primadas" y los "horizontes urbanos inalterados" de las pequeńas y medianas urbes. De hecho, las ciudades medias son buenas para ser estudiadas: tienen un tamaño manejable para entenderlas y mantener a la vista sus detalles, suelen contar con fuentes suficientes, poseen capacidades económicas, políticas y sociales, y entablan relaciones directas con otras poblaciones pequeńas y con grandes ciudades. En apariencia, las urbes pequeñas son menos interesantes, pero una posible ruta para estudiarlas es comparativamente, tomando casos semejantes por su cercanía o por algún tipo de rasgo común (sus actividades económicas, su tamaño, su lugar en una red más grande de ciudades, etcétera). 
8. En la historia urbana reciente hay conceptos "estandarizados", de moda, que hay que poner a prueba: en primer lugar, los fundamentales: "pueblo", "ciudad", "urbano", "urbanización", "rural"; luego uno recurrente y acaso nocivo: "modernización”; pero detrás, también los de "industrialización”, “oposición campo-ciudad”, "urbanismo", "espacio público", "agentes”; y todos los "pre" (casi todos influenciados por autores positivistas o marxistas): preurbano, premoderno, preindustrial.

9. Que estén abiertos a experiencias urbanas diversas; por ejemplo, los estudiosos de la ciudad latinoamericana tienen sobradas razones para conocer las trayectorias de las ciudades europeas y norteamericanas, pero también viceversa.

10. Que eviten el aislamiento, el muro académico, otorgando el valor necesario al trabajo de campo, al conocimiento directo de la ciudad, en procesos abiertos que pongan a prueba los resultados de investigación y que se enriquezcan en el intercambio entre profesionales, habitantes, autoridades o activistas.

11. Que no olviden las lecciones básicas de los Annales: historia problema, historia comparativa, historia dinámica. Una historia que identifique nuevos problemas y explore nuevas rutas para los temas en discusión (ya sea globalización, segregación, crecimiento, gentrificación, patrimonio, etcétera).

A estas ideas aquí apenas esbozadas deberían añadirse dos más. La historia urbana, en primer lugar, como la historia en general, debería ampliar y renovar permanentemente su diálogo con otras disciplinas; pero, más aún, debería abrir un diálogo sostenido con el presente, con los problemas urbanos contemporáneos y con las formas en que se estudian. Si algunas disciplinas sociales han sido dominantes en los estudios urbanos y han perdido de vista la perspectiva histórica, tampoco los historiadores han sido del todo sensibles a la necesidad de estudiar la ciudad y de vincular su pasado con su presente, una posibilidad que en alguna medida proporciona el mirador de los estudios sobre el patrimonio urbano.

En segundo lugar, la "historia urbana" debería preocuparse muy poco por esa etiqueta para aprovechar sus posibilidades: diluir las falsas disputas y las fronteras, dejando de lado los rigurosos márgenes impuestos en el afán de hacer una historia de la arquitectura, una historia del urbanismo, una historia de la planificación, una historia social, una historia cultural o una historia cultural urbana.

Roto el molde, la historia urbana no queda como un campo de estudio sin identidad, sino como un punto de partida para problematizar, para entender mejor esa realidad históricamente construida, multiforme, para recuperar la vieja idea de Fernand Braudel (1984): "El espacio, fuente de explicación, hace intervenir a la vez a todas las realidades de la historia, todas las partes importantes de la extensión: los Estados, las sociedades, las culturas, las economías" (v. III, p. 6). 


\section{Referencias bibliográficas}

Almandoz, A. (2002). Notas sobre historia cultural urbana. Una perspectiva latinoamericana. Perspectivas urbanas, (1). http://www.raco.cat/index.php/Perspectivas/article/view/849 72.

Almandoz, A. (2008). Entre libros de historia urbana. Para una historiografía de la ciudad y el urbanismo en América Latina. Caracas: Equinoccio - Universidad Simón Bolívar.

Álvarez, R., Arana, M. \& Bocchiardo L. (1986). El Montevideo de la expansión (1868-1915). Montevideo: Ediciones de la Banda Oriental.

Augé, M. (2007). El oficio de antropólogo. Sentido y libertad. Barcelona: Gedisa.

Bacon, P. (2005 [1984]). Silver cities: photographing American Urbanization, 1839-1939. Albuquerque, NM: University of New Mexico Press.

Baxandall, M. (1978). Pintura y vida cotidiana en el Renacimiento. Arte y experiencia en el Quattrocento. Barcelona: Gustavo Gilli.

Benevolo, L. (1975). Storia della città. Roma-Bari: Laterza.

Braudel, F. (1984). Civilización material, economía y capitalismo. Siglos XV-XVIII. Vol. 3: El tiempo del mundo. Madrid: Alianza.

Briggs, A. (1963). Victorian cities. Berkeley, CA: University of California Press.

Burke, P. (2001). Visto y no visto. El uso de la imagen como documento histórico. Barcelona: Crítica.

Capel, H. (1998). Una bibliografía para el estudio de la ciudad. Biblio 3W. Revista bibliográfica de Geografia y Ciencias Sociales, 114. http://www.ub.edu/geocrit/b3w-114.htm

Coll, A. (coord.). (2007). Nuevo Atlas Nacional de México. México, D.F.: Universidad Nacional Autónoma de México (UNAM) - Instituto de Geografía.

De Mattos, C. (2016). Lógica financiera, geografía de la financiarización y crecimiento urbano mercantilizado. En A. Orellana, F. Link \& J. Noyola, Urbanización planetaria y la reconstrucción de la ciudad (pp. 29-55). Santiago de Chile: RIL editores - Instituto de Estudios Urbanos y Territoriales, Pontificia Universidad Católica de Chile.

De Ramón, A. (2000). Santiago de Chile. Historia de una sociedad urbana. Santiago de Chile: Sudamericana.

De Terán, F. (1996). Historia urbana moderna en Espańa. Recuento y acopio de materiales. Ayer (23), 87-107. http://oa.upm.es/11852/ df

Duby, G. (1980-1985). Histoire de la France urbaine (5 tomos). París: Seuil.

Dym, J. \& Offen, K. (eds.). (2011). Mapping Latin America. A cartographic reader. Chicago, IL: The University of Chicago Press.

Dym, J. (2010). Mapeando patrias chicas y patrias grandes: cartografía e historia iberoamericana, siglos XVIII-XX. Araucaria. Revista Iberoamericana de Filosofía y Humanidades, 12(24), 99-109. https://revistascientificas.us.es/index.php/araucaria/article/view/1288/1182

Gross, P., De Ramón, A. \& Vial, E. (1984). Imagen ambiental de Santiago, 1880-1930. Santiago de Chile: Ediciones Universidad Católica de Chile.

Hall, P. (1998). Cities in civilization. Culture, innovation, and urban order. Londres: Weidenfeld \& Nicolson.

Hardoy, E. (1991). Cartografía urbana colonial de América Latina y el Caribe. Buenos Aires: Instituto Internacional de Medio Ambiente y Desarrollo - América Latina / Grupo Editor Latinoamericano. 
Harley, J. B. (2006). La nueva naturaleza de los mapas: ensayos sobre la historia de la cartografía. México, D.F.: Fondo de Cultura Económica.

Harvey, D. (2013). Ciudades rebeldes. Del derecho de la ciudad a la revolución urbana. Madrid: Akal.

Hobsbawm, E. (1995). Historia del siglo XX. 1914-1991. Barcelona: Crítica.

Holzapfel, R. N. (1992). Stereographs and stereotypes: a 1904 view of Mormonism. Journal of Mormon History, 18(2), 155-176. https://www.jstor.org/stable/23286406

Kagan, R. L. (2000). Urban images of the Hispanic World, 1493-1793. New Haven, ст: Yale University Press.

Kingman, E. (1989). Las ciudades en la historia. Quito: Centro de Investigaciones Ciudad Consejo Nacional de Universidades y Escuelas Politécnicas - Facultad de Arquitectura y Urbanismo - Universidad Central.

Kostof, S. (1991). The city shaped. Urban patterns and meanings through history. Londres: Thames and Hudson.

Leidenberger, G. (2004). Proximidad y diferenciación: el manejo del concepto del espacio en la historiografía urbana. Historia y Grafia, 11(22), 51-77.

Lepetit, B. (1992). Propuestas para un ejercicio limitado de la interdisciplina. Iztapalapa, 26, 25-36.

Lepetit, B. (1996). Las ciudades en la Francia moderna. México, D.F.: Instituto Mora.

Martínez, G. (2007). Élite, proyecto urbano y fotografía. Un acercamiento a la ciudad de Aguascalientes a través de imágenes, 1880-1914. Secuencia. Revista de historia y ciencias sociales, 67, 145-181. https://doi.org/10.18234/secuencia.v0i67.996

Martínez, G. (2017). La experiencia urbana. Aguascalientes y su abasto en el siglo XX. México, D.F.: Instituto Mora - Universidad Autónoma de Aguascalientes - Universidad de Guanajuato.

Martínez, G. (2018). Urban historiography in Latin America: A comparative perspective of research routes. Urban History. http://dx.doi.org/10.1017/S096392681800072X

Mejía, G. (1998). Pensando la historia urbana. En G. Mejía \& F. Zambrano (coords.), La ciudady las ciencias sociales (pp. 47-73). Bogotá: CEJA.

Mejía, G. (2013). La aventura urbana de América Latina. Madrid: Fundación Mapfre / Taurus.

Morales, D. \& Gayón, M. (2001). Viviendas, casas y usos de suelo en la ciudad de México, 1848-1882. En R. Loreto (coord.), Casas, viviendas y hogares en la historia de México (pp. 339-377). México, D.F.: El Colegio de México.

Morin, E. (2007). La mente bien ordenada. Barcelona: Seix Barral.

Morris, A. (1984). Historia de la forma urbana. Desde sus origenes hasta la revolución industrial. Barcelona: Gustavo Gili (original publicado en 1974: History of urban form. Before the industrial revolutions).

Mumford, L. (1966). La ciudad en la historia. Sus origenes, transformaciones y perspectivas (2 tomos). Buenos Aires: Ediciones Infinito (original publicado en 1961: The city in history: its origins, its transformation, and its prospects).

Pinol, J. (dir.). (2010-2012). Historia de la Europa urbana. Valencia: Universitat de València. (6 tomos: I. La ciudad antigua; II. La ciudad medieval; III. La ciudad moderna; IV. La ciudad contemporánea hasta la Segunda Guerra Mundial; v. La ciudad europea de ultramar; vi. La ciudad contemporánea desde la Segunda Guerra Mundial hasta nuestros días. 
Quesada, F. (2011). Modernización entre cafetales. San José de Costa Rica, 1880-1930. San José: Universidad de Costa Rica.

Ribera, E. \& Aguayo, F. (2014). Imágenes y ciudad. Orizaba a través de la lente, 1872-1910. México, D.F.: Instituto Mora.

Roca, L. (2011). La fotografía aérea en México para el estudio de la ciudad: el crucero de El Caballito. Anais do Museu Paulista: História e Cultura Material, 19(2). http://dx.doi. org/10.1590/S0101-47142011000200004

Romero, J. (1999). Latinoamérica: las ciudades y las ideas. Medellín: Universidad de Antioquia.

Rose, G. (2014). Visual culture, photography, and the urban: an interpretive framework. Space and Culture, India, 4-13. https://doi.org/10.20896/saci.v2i3.92

Schnore, L. F. (1975). Further reflections on the "new" urban history: a prefatory note. En L. F. Schnore, The new urban history. Quantitative explorations by American Historians (pp. 3-11). Princeton, NJ: Princeton University Press.

Schorske, C. (2011). La Viena de fin de siglo. Politica y cultura. Buenos Aires: Siglo XxI Editores (original publicado en 1980: Fin-de-siecle Vienna: politics and culture).

The History of Cartography (1987-2007). 6 vols. Chicago, IL: University of Chicago Press.

Torres, L., Chueca, F. \& González, J. (1951). Planos de ciudades iberoamericanas y filipinas. Madrid: Instituto de Estudios de Administración Local.

Valladares, L. \& Prates, M. (s/f). La investigación urbana en América Latina. Tendencias actuales y recomendaciones. Documentos de debate, núm. 4. Unesco - Programa de Gestión de las Transformaciones Sociales (MOST), http://www.unesco.org/most/vallspa.htm

Wallerstein, I. (1997). La historia de las Ciencias Sociales. México, D.F.: Universidad Nacional Autónoma de México (UNAM) - Centro de Investigaciones Interdisciplinarias en Ciencias y Humanidades. 